\title{
The effects of claw ligatures in American lobster (Homarus americanus) storage: a preliminary study of haemolymph parameters
}

\author{
Chiara Coppola $^{1}$, Erica Tirloni ${ }^{1}$, Mauro Vasconi ${ }^{1}$, Aniello Anastasio ${ }^{2}$, Simone Stella $^{1}$, \\ Cristian Bernardi ${ }^{1}$ \\ ${ }^{1}$ University of Milan, Faculty of Veterinary Medicine, Department of Health, Animal Science and Food Safety \\ Laboratory of Food Inspection, Milan, Italy \\ ${ }^{2}$ University of Naples “Federico II”, Faculty of Veterinary Medicine, Department of Veterinary Medicine and \\ Animal Production, Naples, Italy
}

Received May 2, 2019

Accepted June 13, 2019

\begin{abstract}
American lobsters are crustaceans that are offered for sale live and are stored in controlled temperature recirculating aquaria. During marketing, they are subjected to stressors that can affect their welfare, such as air exposure, confinement, and handling. European legislation does not provide specific criteria or retention requirements, and so their management depends largely on the common sense of food business operators. Claw ligatures before and during storage are not legally required but are recommended because they prevent lobsters from damaging each other and ensure workers' safety. The aim of the present study is to evaluate the effect of claw ligatures on the lobsters' welfare by analysing eight different haemolymph stress indicators, vitality, and weight. The calcium level showed significant differences in the two experimental groups $(P<0.05)$. Our results suggested that the absence of rubber bands did not offer any significant contribution to the lobsters' welfare.
\end{abstract}

Claws binding, Crustacea, stress response, invertebrates

European legislation (European Commission 2004) defines crustaceans as seafood, therefore, they can be commercialized when dead. However, keeping these animals alive gives the best commercial quality and buying live animals is considered a good and fair practice by many consumers. Furthermore, these animals are highly perishable, and they can exhibit off-odours and deterioration of organoleptic qualities within a short period after death. In contrast to the practices of other countries (e.g., Norway, Australia, and New Zealand) where specific guidelines and regulations on animal welfare apply to these decapod crustaceans (Bennison 2002; Johnston and Jungalwalla 2005), in Europe the current norm is to set minimum standards for animal storage and provide only guidelines for invertebrate welfare, such as those from the Scientific Panel on Animal Health and Welfare (EFSA 2005) and of the Sea Fish Industry Authority (Jacklin and Combes 2007), a public body in the United Kingdom. Stress factors and poor welfare can lead to increased susceptibility to diseases among animals (EFS A 2005) and this can pose risks to consumers (e.g., food-borne infections) (European Commission 2004). Thus, handling and conservation of these animals during marketing are practices that must meet welfare requirements (Candotti 2007).

The Swiss Government took a step forward in acknowledging and promoting invertebrate welfare by modifying the Swiss Animal Protection Ordinance (Swiss Federal Council 2018). The new regulation (Art. 23) establishes that from $1^{\text {st }}$ March 2018, live decapods cannot be transported on ice or in icy water, and species that naturally live underwater must always be held in this environment. Furthermore, decapods must be stunned before slaughtering and only electric shocks or the "mechanical destruction" of the brain are accepted (Art. 178). 
Extensive research worldwide has considered the welfare of crustaceans (Lorenzon et al. 2007; Basti et al. 2010; D'Agaro et al. 2014), and the physiological responses of lobsters to external stressors such as confinement, starvation, air exposure and temperature have been evaluated by measuring different biochemical parameters. The sampling of haemolymph is a non-destructive method which is commonly used to quantify physiological stress in crustaceans. Lobsters are solitary animals, and in order to avoid competitiveness, cannibalism and operator injuries, their claws are kept clasped before and during storage. This condition has been considered to be highly restrictive, as lobsters use their claws for locomotion, feeding and defence, but there is a lack of scientific evidence for this. Thus, the aim of the present study was to investigate haemolymph stress parameters, vitality and weight to assess if claw ligatures may influence lobster welfare.

Animals and experimental design

\section{Materials and Methods}

American lobsters were transported by air at refrigeration temperatures $\left(-3\right.$ to $\left.-4{ }^{\circ} \mathrm{C}\right)$ in cardboard boxes containing ice gel packs. Upon arrival at the Italian distribution platform, the subjects were evaluated for vitality by applying the Vitality Index (Crustasea 2006) and for sanitary status. Only animals with a Vitality Index of 5 (strong) were included in the trial, defined by the following criteria: animals had very strong claws and walking legs, showed strong uropod movement, rigid uropod, aggressive or defensive attitude and reactive antennae (sick or suspected animals were thus excluded). The use of live animals was necessary in the in vivo stages of this work, and they were treated with due care, minimizing discomfort and distress. According to the 3 Rs principle (Replacement, Reduction, Refinement), the number of animals used was the minimum necessary for obtaining satisfactory scientific results.

The trial was conducted in the Lodi Aquaculture Research Centre at the University of Milan. A total of 24 American lobsters of both sexes, with live masses of $485.11 \pm 10.77 \mathrm{~g}$ (mean weight \pm S.D.), were assigned randomly to one of two experimental groups: a control group $(C)$, in which subjects were maintained free in the tank with tied claws, and a treatment group $(\mathrm{T})$ where the subjects were held in single plastic cages $(30 \mathrm{~cm}$ length $\times 18 \mathrm{~cm}$ width $\times 10 \mathrm{~cm}$ height $)$ with free claws. The animals were transferred to a commercial aquarium $(148 \mathrm{~cm}$ length $\times 58 \mathrm{~cm}$ width $\times 70 \mathrm{~cm}$ height - Adriatic Sea International, Ravenna, Italy) containing artificial seawater and equipped with a recirculating system. The animals were maintained unfed throughout the trial. Haemolymph samples were collected from the ventral abdominal sinus (arthrodial membrane covering the articulated base of the $5^{\text {th }}$ walking leg) of each subject at arrival before the immersion (T0) and after $12 \mathrm{~h}$ (T1), $36 \mathrm{~h}$ (T2), 60 h (T3) and $108 \mathrm{~h}$ (T4) of immersion, as described by Bernardi et al. 2015.

The Vitality Index and weight were measured at the same sampling times. Water temperature and dissolved oxygen were recorded daily with a Hach HQ 30d portable meter, (Hach Lange, Düsseldorf, Germany). The water temperature was $6.0 \pm 0.2^{\circ} \mathrm{C}$ and the oxygen concentration was near the saturation, with a minimum recorded value of $87 \%$. Water salinity was measured by gravity and it remained stable at a value of 1020 . Total ammonia and nitrites, measured in each aquarium at every sampling event with a Hach 2800 Portable Spectrophotometer (Hach Lange, Düsseldorf, Germany), were below $0.05 \mathrm{mg} \cdot \mathrm{l}^{-1}$, except for an increase recorded at $12 \mathrm{~h}$, when the ammonia was $0.45 \mathrm{mg} \cdot \mathrm{l}^{-1}$ for group $\mathrm{C}$ and $0.51 \mathrm{mg} \cdot \mathrm{l}^{-1}$ for group $\mathrm{T}$, probably due to the high amount of ammonia released by lobsters when they were returned to the water after transport.

Determination of haemolymph parameters

Eight different physiological parameters were determined for each sample: glucose, total protein, lactate, ammonia, urea, chloride, calcium and magnesium concentrations. The ammonia content was quantified with the Ammonia Checker II (Menarini Diagnostics, Florence, Italy) and commercial kit test strips Ammonia test Kit II (Menarini Diagnostics, Florence, Italy). Glucose, total protein, lactate, chloride, calcium, magnesium and urea were determined using the COBAS MIRA biochemistry analyser (Roche Diagnostic, Monza, Italy). The following kits were adopted: Glucose Quantitative Colorimetric Assay Kit (Biochemical Enterprise, Milan, Italy), Total Protein Quantitative Colorimetric Assay Kit (Biuret method) (Biochemical Enterprise, Milan, Italy), Lactate Dry-Fast Enzymatic Colorimetric Assay Kit (Sentinel Diagnostics, Milan, Italy), Chloride Quantitative Colorimetric Assay Kit (mercuric thiocyanate method) (Biochemical Enterprise, Milan, Italy), Calcium Colorimetric Assay Kit (o-cresolftalein complexone method) (Hagen Diagnostica, Florence, Italy), Magnesium Colorimetric Assay Kit (Xylidyl Blue - I Method) (AdipoGen Life Sciences, Liestal, Switzerland), Urea Quantitative Kinetic Assay (Biochemical Enterprise, Milan, Italy).

\section{Statistical analyses}

A three-factor (experimental group, time and sex) analysis of covariance (the covariates were the vitality index and weight) was conducted to analyse the data. The weight effect was of interest while sex was added to the model as a known confounding factor. The data analysis was generated using RStudio Software, Version 0.98.1103. $P$ values of less than 0.05 were considered significant. 


\section{Results}

The experimental values (mean \pm S.D.) of the studied variables are reported in Table 1 . During the trial one treated lobster and one control lobster died after $108 \mathrm{~h}$ of storage in the tank, so they were not sampled.

The mean vitality at arrival was similar in both groups $(4.58 \pm 0.51$ in group $C$; $4.50 \pm 0.67$ in group $\mathrm{T}$ ), and it reached $5.00 \pm 0.00$ after $12 \mathrm{~h}$ and remained stable in all individuals until $108 \mathrm{~h}$. Vitality significantly increased after $12 \mathrm{~h}$ in group $\mathrm{C}$ and T. No difference between the control group and the treated group was detected.

Weight increased during the sampling times. On average, the control group gained $22.46 \mathrm{~g}$ (108 h mean weight: $514.80 \pm 45.68 \mathrm{~g})$ and the treatment group $23.22 \mathrm{~g}$ (108 $\mathrm{h}$ mean weight: $501.11 \pm 32.54 \mathrm{~g}$ ). Weight recovery after $12 \mathrm{~h}$ was significant, while no significant differences were recorded between the two groups.

The average glucose concentration at arrival was $3.54 \pm 2.92 \mathrm{mg} \cdot \mathrm{dl}^{-1}$. Both treated and control animals showed significant decreases in haemolymph glucose after $12 \mathrm{~h}$. Minimum variations were recorded during the subsequent sampling times. Differences in glucose levels between the groups were not significant $(P=0.20)$.

A higher concentration of lactate upon arrival was found in all the individuals (average level $\left.9.91 \pm 10.74 \mathrm{mg} \cdot \mathrm{dl}^{-1}\right)$. Lactate concentration significantly decreased after $12 \mathrm{~h}$, but it showed no significant difference between control and treated subjects $(P=0.62)$.

The average protein value at arrival was $1.78 \pm 0.54 \mathrm{~g} \cdot \mathrm{dl}^{-1}$ and the subsequent measurements showed a similar trend. An exception is the protein values after $108 \mathrm{~h}$, which increased and almost returned to those at the arrival time. Significant differences were detected in protein concentration after immersion in tank, while the differences between the groups were not significant $(P=0.06)$.

A significant difference in ammonia concentration was found between arrival time and after $12 \mathrm{~h}$ of storage. A higher concentration at arrival was found (average level at T0 vs. $\mathrm{T} 1: 2.75 \pm 1.08 \mathrm{mg} \cdot \mathrm{dl}^{-1}$ vs. $1.27 \pm 4.27$ ). Haemolymph ammonia also increased after $36 \mathrm{~h}$, and after $108 \mathrm{~h}$ it reached levels close to those of arrival. Ammonia $P$ value between the groups was not significant $(P=0.09)$.

Urea levels between T0 and T1 were significantly different. A higher urea level was found at arrival. The parameter increased after $36 \mathrm{~h}$ of storage and variations were recorded during the subsequent sampling times. Urea levels were not significantly different between the groups $(P=0.14)$.

The average chloride concentration at arrival was $451.46 \pm 10.93 \mathrm{mmol} \cdot \mathrm{l}^{-1}$ and it decreased to $439.58 \pm 14.05 \mathrm{mmol} \cdot \mathrm{l}^{-1}$ after $12 \mathrm{~h}$. This difference was significant, while chloride $P$ value between the groups was not significant $(P=0.44)$.

Calcium concentrations at arrival were significantly higher $(P<0.001)$ compared to the other sampling times. The subsequent detections showed a similar pattern. Calcium levels showed a significant difference $(P<0.05)$ also between the treatment and control group.

The mean magnesium value at arrival was $6.23 \pm 0.21 \mathrm{mg} \cdot \mathrm{dl}^{-1}$ in the control group and $6.10 \pm 0.24 \mathrm{mg} \cdot \mathrm{dl}^{-1}$ in the treatment group. At the subsequent times, minimum variations in both groups were highlighted. The present study did not show a significant modification of magnesium concentrations either between T0 and T1, or between the groups $(P=0.12)$.

\section{Discussion}

The effect of immersion in the tank

Significant differences were detected in the vitality, weight and haemolymph parameters between arrival (T0) and after $12 \mathrm{~h}$ of immersion (T1) in both groups. 


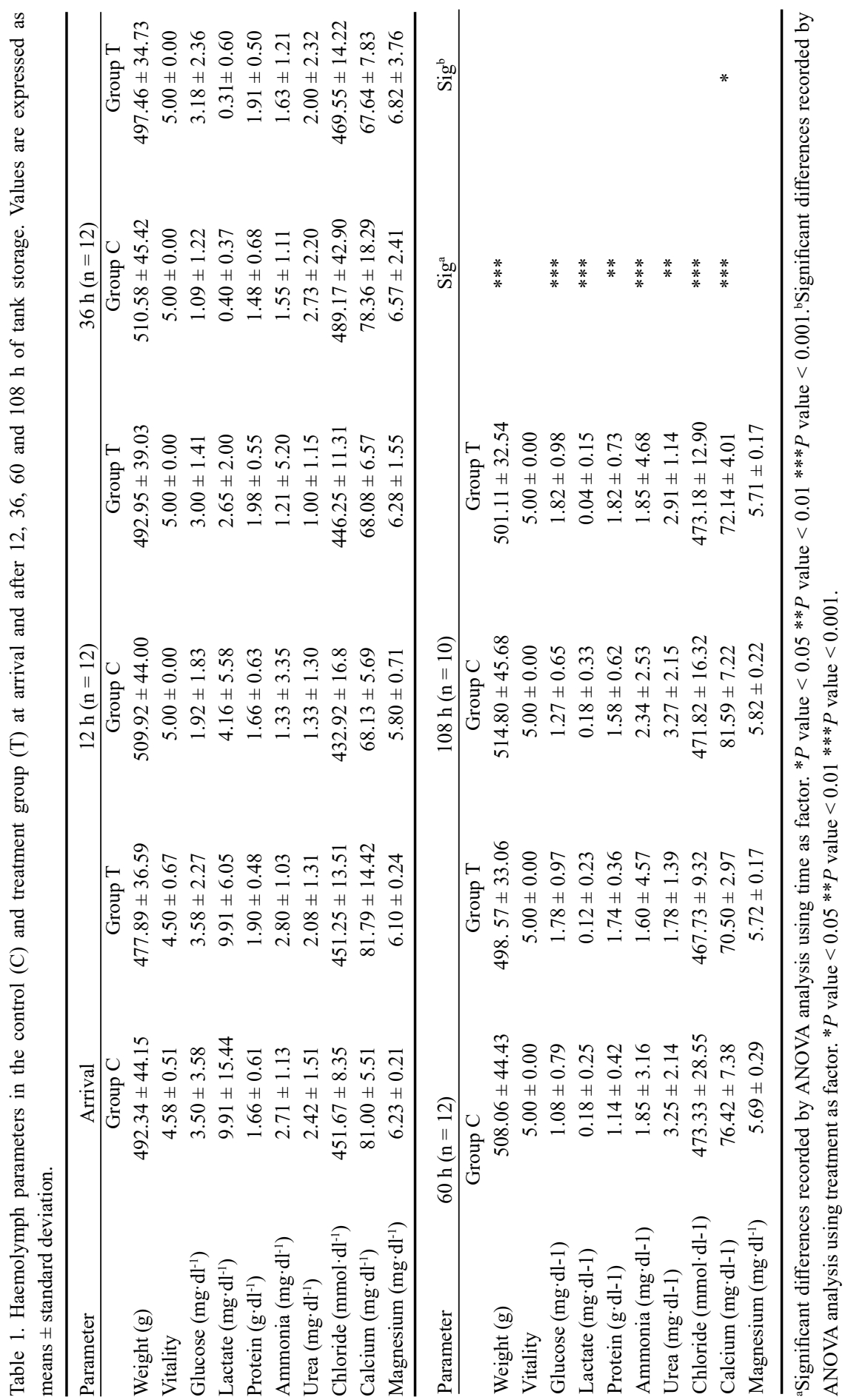


The increase in vitality and weight detected after $12 \mathrm{~h}$ and during the subsequent times may be due to the effects of water loss during transport (exposure to air) and the subsequent water intake during storage, as others have also reported (D'Agaro et al. 2014).

The haemolymph glucose content is an indicator of distress status: crustacean hyperglycaemic hormone $(\mathrm{cHH})$ increases in response to air exposure and high temperature (Lorenzon et al. 2007). High glucose concentration at arrival may be related to air exposure, which leads to glucose mobilization for anaerobic metabolism, while the glucose decrease after $12 \mathrm{~h}$ may be due to the reduction of stress linked to air exposure. In the present study, the glycaemia remained under the resting value reported by Lorenzon et al. $2007\left(12.07 \pm 3.42 \mathrm{mg} \cdot \mathrm{dl}^{-1}\right)$.

The lactate concentrations observed upon arrival differ from those obtained in previous studies (Lorenzon et al. 2007; Bernardi et al. 2015), where it was found that the mean lactate concentrations at arrival were $24.41 \pm 17.65 \mathrm{mg} \cdot \mathrm{dl}^{-1}$ and $52.23 \mathrm{mg} \cdot \mathrm{dl}^{-1} \pm 12.30$, respectively. This difference could be related to the batch variability in the studies: subjects chosen in the aforementioned trials probably had already higher lactate concentrations prior to T0. The increase of lactate concentration during aerial exposure is indicative of anaerobic metabolism and may be due to an inadequate supply of oxygen to tissues. The lactate decrease after $12 \mathrm{~h}$ is equivalent to the results of Lorenzon et al. 2007, in which it decreased after $12 \mathrm{~h}$ in storage tanks, presumably due to a better level of oxygenation that reduced anaerobic metabolism and subsequent lactate production.

The mean protein value at arrival is equivalent to the results of Bernardi et al. 2015. Haemolymph protein in lobster is influenced by molting and nutrition, and it increases when lobsters are subjected to high temperature and hypoxia: $80-90 \%$ of protein is represented by haemocyanin (Lee and Chen 2003; Brouwer et al. 2004; Chausson et al. 2004). This increases the amount of oxygen that can be delivered to the tissues, which may explain the low protein concentrations obtained in the present study, as the temperature remained constant during the trial and air exposure was only present during transport. The death of two animals after $108 \mathrm{~h}$ may have increased the lobsters' metabolic activity, resulting in a higher demand for protein as an energy store. However, we were not able to verify this assumption.

Nitrogen is mainly excreted as ammonia in aquatic crustaceans, either by diffusion or $\mathrm{Na}^{+} / \mathrm{NH}_{4}^{+}$exchange across the gills (Evans and Cameron 1986). The ammonia values observed at arrival were comparable with those found by Bernardi et al. 2015 $\left(2.92 \pm 0.32 \mathrm{mg} \cdot \mathrm{dl}^{-1}\right)$. The higher ammonia concentrations at arrival may be due to gill dysfunction during air exposure interfering with the catabolite diffusion. However, gill irrigation during the immersion allowed for catabolite exchange and led to a decrease in ammonia after $12 \mathrm{~h}$. The reason for the increment detected after $36 \mathrm{~h}$ and $108 \mathrm{~h}$ is not currently known.

Urea is linked to toxicity status and directly increases with salinity (Lee and Chen 2003). High urea concentrations at arrival were due to the physiological response to air exposure: toxic compounds, as they cannot be eliminated through the gills, are then converted to urea, which is less toxic. The same results were highlighted by Bernardi et al. 2015 who found that urea production increased in Homarus americanus subjects maintained exposed to air. The reason for the increase of urea detected after $36 \mathrm{~h}$ remains unclear.

Hypoxia and high temperatures generally reduce chloride concentrations in crustaceans (Cheng et al. 2003). These conditions increase anaerobic metabolism and lactate production with the subsequent activation of the $\mathrm{Cl}^{-} / \mathrm{HCO}_{3}{ }^{-}$exchange system, which leads to haemolymph chloride reduction. Despite the aerial exposure, chloride values at arrival were close to the physiological level $\left(449.29 \pm 3.57 \mathrm{mmol}^{-1} \mathrm{l}^{-1}\right)$ reported by Lorenzon et al. 2007. The low chloride concentration after $12 \mathrm{~h}$ suggests that aerial stress at arrival 
negatively influenced the recovery time in the tank. In the present study a positive correlation between chloraemia and immersion was found, starting from $36 \mathrm{~h}$.

Calcium concentrations at arrival were found to be equivalent to those of Bernardi et al. 2015 (our study vs. that of Bernardi et al.: $81.39 \mathrm{vs.} 83.43 \pm 1.40 \mathrm{mg} \cdot \mathrm{dl}^{-1}$ ), although their study showed no significant difference between T0 and T1. The calcium levels in crustaceans fluctuate in response to ecdysis, water salinity and lactate concentration. Due to the high lactate concentration, the calcium concentrations at arrival were significantly higher than those after $12 \mathrm{~h}$. Calcium is mobilized from the exoskeleton as $\mathrm{CaCO}_{3}$, and acts as a buffer against further acidosis (Taylor and Whiteley 1989) and improves the affinity of haemocyanin for oxygen under anaerobic conditions (Bridges 2001; Dove et al. 2005). However, there is only indirect evidence that this $\mathrm{Ca}$ originates in the exoskeleton (Wheatly 1996). The subsequent detections showed a similar pattern, despite the calcium levels remaining higher than the physiological level of $64.4 \mathrm{mg} \cdot \mathrm{dl}^{-1}$ (Lorenzon et al. 2007).

Magnesium in crustaceans contributes to the maintenance of high haemocyanin affinity for oxygen and can be used as a compensatory mechanism for coping with hypoxia (Truchot 1975; McMahon 2001). However, the present study did not show a significant modification of magnesium levels between $\mathrm{T} 0$ and $\mathrm{T} 1$. This result is also in contrast with that of Bernardi et al. 2015) who found a significant difference between arrival and immersion (12 h) times.

\section{The effect of claw ligature}

Significant differences between group $\mathrm{C}$ and $\mathrm{T}$ were detected exclusively in calcium values. The constant pattern observed in haemolymph calcium concentrations suggests that calcium is highly regulated in lobsters, which is consistent with other findings on their calcium metabolism (Wheatly 1996; McMahon 2001). Nevertheless, with our current level of knowledge, we are not able to assess the relation between haemolymph calcium and claw ligature.

In conclusion, the results of the present study show that claw ligature in American lobsters did not have a significant effect on vitality, weight and haemolymph parameters except for calcium, and currently we are not able to explain why and how the treatment affected this parameter. Therefore, further investigations are required. The significant effect of immersion on all of the parameters confirms what previous studies have demonstrated, and particularly the importance of storage in tanks with high quality artificial seawater, to reduce metabolic distress. As our results suggested that the rubber bands did not affect the haemolymph parameters linked to stress, and since the absence of claw ligatures can enhance aggressive behaviour among subjects and difficulties in animal handling by food business operators, the habit of keeping lobster's claw blocked can be considered a good operating practice in the trade of live lobsters. However, our study focused only on haemolymph parameters and for a limited time, so the final decision on the effects of claw ligatures on lobsters' welfare cannot be made without further research on the both shortand long-term effects, especially concerning behaviour and pain. Future investigations should also be considered regarding haemolymph parameters as useful indicators of poor lobster welfare and/or stressful conditions.

\section{Acknowledgements}

The authors would like to acknowledge Carlotta Dotti for assistance during the experiments.

\section{References}

Basti D, Bricknell I, Hoyt K, Bouchard DA 2010: Factors affecting post-capture survivability of lobster Homarus americanus. Dis Aquat Organ 90: 153-166 
Bennison S 2002: Guidelines On Aquatic Animal Welfare For The Aquaculture Industry In Western Australia, $22 \mathrm{p}$.

Bernardi C, Baggiani L, Tirloni E, Stella S, Colombo F, Moretti VM, Cattaneo P 2015: Hemolymph parameters as physiological biomarkers in American lobster (Homarus americanus) for monitoring the effects of two commercial maintenance methods. Fish Res 161: 280-284

Bridges CR 2001: Modulation of haemocyanin oxygen affinity: properties and physiological implications in a changing world. J Exp Biol 204: 1021-1032

Brouwer M, Larkin P, Brown-Peterson N, King C, Manning S, Denslow N 2004: Effects of hypoxia on gene and protein expression in the blue crab, Callinectes sapidus. Mar Environ Res 58: 787-792

Candotti P 2007: Sofferenza di aragoste e astici vivi con chele legate e su letto di ghiaccio durante la fase di commercializzazione. Available at: https://www.izsler.it/izs_bs/allegati/2250/ASTICIVIVI.pdf. Accessed January 24, 2018

Chausson F, Sanglier S, Leize E, Hagège A, Bridges CR, Sarradin PM, Shillito B, Lallier FH, Zal F 2004: Respiratory adaptations to the deep-sea hydrothermal vent environment: the case of Segonzacia mesatlantica, a crab from the Mid-Atlantic Ridge. Micron 35: 31-41

Cheng W, Liu CH, Kuo CM 2003: Effects of dissolved oxygen on hemolymph parameters of freshwater giant prawn, Macrobrachium rosenbergii (de Man). Aquaculture 220: 843-856

Crustasea 2006: Development of best practice, grading \& transportation technology in the crustacean fishery sector with emphasis on the edible crab (Cancer pagurus) \& the Norway Lobster (Nephrops norvegicus). Available at: https://cordis.europa.eu/project/rcn/84917 en.html. Accessed: November 22, 2018

D’Agaro E, Sabbioni V, Messina M, Tibaldi E, Bongiorno T, Tulli F, Lippe G, Fabbro A, Stecchini M 2014: Effect of confinement and starvation on stress parameters in the (Homarus americanus). Ital J Anim Sci 13: 891-896

Dove ADM, Sokolowski MS, Bartlett SL, Bowser PR 2005: Spatio-temporal variation in serum chemistry of the lobster, Homarus americanus Milne-Edwards. J Fish Dis 28: 663-675

EFSA 2005: Opinion on the 'Aspects of the biology and welfare of animals used for experimental and other scientific purposes'. EFSA J 3: 292

European Commission 2004: Council Regulation (EC) No853/2004 of the European Parliament and of the Council Laying down Specific Hygiene Rules for on the Hygiene of Foodstuffs. Off J Eur Union L 139/55: 1-81

Evans DH, Cameron JN 1986: Gill ammonia transport. J Exp Zool 239: 17-23

Jacklin M, Combes J 2007: The good practice guide to handling and storing live Crustacea. Sea Fish Ind Auth Publ UK, $151 \mathrm{p}$.

Johnston C, Jungalwalla P 2005: Guidelines on Welfare of Fish and Crustaceans in Aquaculture and/or in Live Holding Systems for Human Consumption. National Aquaculture Council of Australia

Lee WC, Chen JC 2003: Hemolymph ammonia, urea and uric acid levels and nitrogenous excretion of Marsupenaeus japonicus at different salinity levels. J Exp Mar Bio Ecol 288: 39-49

Lorenzon S, Giulianini PG, Martinis M, Ferrero EA 2007: Stress effect of different temperatures and air exposure during transport on physiological profiles in the American lobster Homarus americanus. Comp Biochem Physiol - A Mol Integr Physiol 147: 94-102

McMahon BR 2001: Respiratory and circulatory compensation to hypoxia in crustaceans. Respir Physiol 128: 349-364

Swiss Federal Council 2018: Ordinanza sulla Protezione degli Animali - OPAn. Available at: https://www.admin. ch/opc/it/official-compilation/2018/573.pdf. Accessed March 30, 2018

Taylor EW and Whiteley NM 1989: Oxygen transport and acid-base balance in the haemolymph of the lobster, Homarus gammarus, during aerial exposure and resubmersion. J Exp Biol 144: 417-436

Truchot JP 1975: Factors controlling the in vitro and in vivo oxygen affinity of the hemocyanin in the crab Carcinus maenas (L.). Respir Physiol 24: 173-189

Wheatly MG 1996: An overview of calcium balance in crustaceans. Physiol Zool 69: 351-382 